Article

\title{
Does Scientific Uncertainty in News Articles Affect Readers' Trust and Decision-Making?
}

\author{
Friederike Hendriks * and Regina Jucks \\ Department of Psychology and Sport Studies, University of Münster, 48149 Münster, Germany; \\ E-Mails: f.hendriks@uni-muenster.de (F.H.), jucks@uni-muenster.de (R.J.) \\ * Corresponding author
}

Submitted: 23 January 2020 | Accepted: 27 April 2020 | Published: 26 June 2020

\begin{abstract}
Even though a main goal of science is to reduce the uncertainty in scientific results by applying ever-improving research methods, epistemic uncertainty is an integral part of science. As such, while uncertainty might be communicated in news articles about climate science, climate skeptics have also exploited this uncertainty to cast doubt on science itself. We performed two studies to assess whether scientific uncertainty affects laypeople's assessments of issue uncertainty, the credibility of the information, their trust in scientists and climate science, and impacts their decision-making. In addition, we addressed how these effects are influenced by further information on relevant scientific processes, because knowing that uncertainty goes along with scientific research could ease laypeople's interpretations of uncertainty around evidence and may even protect against negative impacts of such uncertainty on trust. Unexpectedly, in study 1 , after participants read both a text about research methods and a news article that included scientific uncertainty, they had lower trust in the scientists' assertions than when they read the uncertain news article alone (but this did not impact trust in climate science or decision-making). In study 2, we tested whether these results occurred due to participants overestimating the scientific uncertainty at hand. Hence, we varied the framing of uncertainty in the text on scientific processes. We found that exaggerating the scientific uncertainty produced by scientific processes (vs. framing the uncertainty as something to be expected) did not negatively affect participants' trust ratings. However, the degree to which participants preferred effortful reasoning on problems (intellective epistemic style) correlated with ratings of trust in scientists and climate science and with their decision-making. In sum, there was only little evidence that the introduction of uncertainty in news articles would affect participants' ratings of trust and their decision-making, but their preferred style of reasoning did.
\end{abstract}

\section{Keywords}

fake news; procedural knowledge; readership; science communication; scientific literacy; scientific uncertainty; trust

\section{Issue}

This article is part of the issue "Health and Science Controversies in the Digital World: News, Mis/Disinformation and Public Engagement" edited by An Nguyen (Bournemouth University, UK) and Daniel Catalan (University Carlos III of Madrid, Spain).

(C) 2020 by the authors; licensee Cogitatio (Lisbon, Portugal). This article is licensed under a Creative Commons Attribution 4.0 International License (CC BY).

\section{Introduction}

Scientific uncertainty is defined as "lack of scientific knowledge, or disagreement over the knowledge that currently exists" (Friedman, Dunwoody, \& Rogers, 2012, p. xiii). While scientific processes are continuously optimized to allow only limited uncertainty, uncertainty remains an immediate outcome of scientific research
(Friedman et al., 2012). Consequently, there has been debate in science communication research and practice about how and to what effect uncertainty may be communicated. Research suggests that communicated uncertainty might lead to adverse reactions by recipients (see National Academies of Sciences, Engineering, and Medicine, 2017). Also, uncertainty has been utilized to manufacture doubt about climate science among 
the general public (Freudenburg, Gramling, \& Davidson, 2008; Lewandowsky, Ballard, \& Pancost, 2015; Oreskes, 2015; Oreskes \& Conway, 2011). However, it has also been argued that transparency about uncertainty in scientific information might enhance public trust, as long as it is not overemphasized (e.g., Druckman, 2015; Zehr, 2017).

In digital media (e.g., social media and blogs), uncertainty is often expressed and explicitly discussed (Dunwoody, Hendriks, Massarani, \& Peters, 2018), but it might also be exploited by climate skeptics to fuel their online attacks. In fact, a number of studies investigating climate-skeptical blogs ascertain that blog entries and comments often challenge scientific data and methods in order to establish the notion there is an active scientific controversy around climate change (Elgesem, Steskal, \& Diakopoulos, 2015; Matthews, 2015; Sharman, 2014). Mercer (2018) concluded that climate skeptics may use appeals to Popper's philosophy (e.g., whether claims of climate science are falsifiable) to deconstruct climate science arguments.

In such a context, we conducted two studies to investigate how the communication of scientific uncertainty within news articles about climate science affects participants' assessment of uncertainty surrounding an issue and their trust in climate researchers and climate science. In the first study, because the scientific processes might act as a source of uncertainty but also as a way to resolve it, we investigated whether reading about scientific processes before reading news articles on climate science might mitigate the effect that communicated scientific uncertainty may have on participants' judgments about issue uncertainty and trust. In the second study, we extend our results by varying how we introduced the scientific processes. We introduced them either by emphasizing that scientific processes are optimized to achieve as much scientific certainty as possible or by exaggerating the scientific uncertainty inherent in science (as climate skeptics might do in digital media).

\subsection{Scientific Uncertainty}

While some uncertainty cannot be resolved (e.g., knowledge about the future), the term 'epistemic uncertainty' pertains to unknowns that can be resolved, at least in theory. Sources of epistemic uncertainty often lie within scientific processes (van der Bles et al., 2019; Walker, 1991). Even though processes and methods are continuously optimized to limit uncertainty, there is always some level of specification that cannot be reached. Walker (1991) prepared a taxonomy of such sources of uncertainty, applicable to a variety of empirical scientific disciplines: When designing research, conceptual uncertainty is present in the choice and conceptual definition of variables. Then, measurement uncertainty arises as related to how consistent and how accurate measurements are. Processes of generalization involve sampling uncertainty, whereas modeling uncertainty refers to errors in esti- mating mathematical relationships between variables. Next, causal uncertainty arises from the possibility of making false assumptions about a variable's causal relationship. Finally, Walker's taxonomy also includes uncertainty stemming from false use or assumptions of knowledge or underlying theories, which may influence all the other types of uncertainty. Following an extensive review of conceptualizations of scientific uncertainty and empirical evidence, van der Bles et al. (2019) added another source of scientific uncertainty: expert disagreement. Expert disagreement may arise when empirical results are new, not yet replicated, or conflicting, but also when experts have not (yet) reached consensus over accumulated evidence (see Oreskes, 2007; Zehr, 2017).

In this article, we refer to scientific uncertainty, which pertains to the status of evidence (but not uncertainty around facts or numbers; for a recent study, see van der Bles, van der Linden, Freeman, \& Spiegelhalter, 2020), and we use Walker's conceptualization to describe how we manipulated scientific uncertainty in both studies. In study 1 , in the news article participants read we included measurement, sampling, and modeling uncertainty around evidence on the effect of climate change on ocean life; in study 2 , we further introduced participants to the uncertainty resulting from expert disagreement.

\subsection{Trust and Decision-Making}

Scientific uncertainty is directly linked to trust in science. While scientific knowledge is inherently uncertain and complex, this also means that a full understanding of scientific claims and evidence is not feasible for laypeople, resulting in a bounded understanding of science (Bromme \& Goldman, 2014). To overcome this bounded understanding, laypeople have to defer to and depend on expert knowledge (Bromme \& Goldman, 2014; Schäfer, 2016), but this does not mean they are gullible (Sperber et al., 2010). Instead, they build trust through heuristically and systematically evaluating information and information sources (Hendriks \& Kienhues, 2019). In trustworthiness evaluations of experts, three dimensions are recognized: an expert's expertise, integrity and benevolence (Hendriks, Kienhues, \& Bromme, 2015). Further, because people likely make similar evaluations of scientific experts and their corresponding scientific communities, people might evaluate whether experts of a particular domain hold and share expertise, follow established and acceptable norms, and act with a general goodwill toward society.

Many studies have investigated the relationship between communicated scientific uncertainty and trust in science or scientists, and results are contradictory. This might be because different studies operationalized the communicated uncertainty differently, e.g., as distributions, ranges, or verbal statements, or because different studies evaluated different sources of uncertainty. In the context of our work, below we only describe studies- 
separately for different dependent variables-that have examined the influence of verbal statements about scientific uncertainty on trust in science or scientists (for a complete review, see van der Bles et al., 2019).

First, some studies have investigated how trustworthy scientists or journalists are perceived to be as information sources when they communicate scientific uncertainty. Gustafson and Rice (2019) found that when they included uncertainty frames related to consensus (i.e., experts disagree) in scientific information on climate change, this lowered the perceived credibility of the source compared to a control condition; conversely, other scientific uncertainty frames (e.g., referring to unknowns within future research) did not. Further, Jensen (2008) found that when disclosed uncertainty was attributed to an article's primary scientist, this enhanced the primary scientist's perceived trustworthiness (here: honesty and transparency) and that of the article's author (journalist). In a later study, this finding was only replicated for journalists' credibility but not for that of scientists (Ratcliff, Jensen, Christy, Crossley, \& Krakow, 2018).

Second, other studies have investigated how trust in a particular scientific discipline is affected when scientific uncertainty is disclosed. For example, when an article describes the limitations (vs. recent advances) of research in a scientific field, the field is perceived to be less precise and less simple (and more so by Republicans than Democrats in a US sample; Broomell \& Kane, 2017). In another study, introducing scientific uncertainty and limitations in news articles about cancer research did not increase trust in the medical profession, but introducing more experts in the article may have (Jensen et al., 2011).

Third, some studies have investigated whether scientific uncertainty affects laypeople's internal uncertainty-their psychological experience of uncertainty (Peters \& Dunwoody, 2016; van der Bles et al., 2019)-which might manifest in people's decisionmaking (e.g., Han, Moser, \& Klein, 2007). In one study, messages that included uncertainty did result in participants giving higher ratings on the objectivity and balance of the journalistic reporting (about a vaccine), but it lowered participants' ease of decision-making (Westphal, Hendriks, \& Malik, 2015). Two other studies used the following variation: Uncertainty was introduced either via lexical hedges (e.g., 'probably') or by referring to other experts. In one study, hedging led participants to more easily make decisions about a health issue (Mayweg-Paus \& Jucks, 2015), while in the other study, hedging in texts about an educational issue led to participants to give lower ratings on argument credibility and 'scientific-ness' of the text (Thiebach, Mayweg-Paus, \& Jucks, 2015).

Taken together, the results on how uncertainty affects laypeople's trust and decision-making are rather inconclusive. Thus, here we investigated whether scientific uncertainty (pertaining to the state of evidence) in news articles affects participants' assessment of uncer- tainty in the research field and affects their trust in assertions made by climate scientists and their trust in climate science itself. Furthermore, we assessed whether being faced with scientific uncertainty led participants to have more uncertainty when making decisions related to the issue.

\subsection{Knowledge about Scientific Processes}

As mentioned above, in science's endeavor to narrow in on the 'truth,' scientific processes are continuously augmented to minimize uncertainty. However, the degree to which laypeople understand such aspects about science is central to their scientific literacy. In newer conceptions of the term, scientific literacy entails not only content knowledge (knowing a set of facts about science) but also procedural and epistemic knowledge (Organisation for Economic Co-operation and Development, 2017). Procedural knowledge means being aware of the main methods of empirical enquiry, as well as the scientific uncertainty that comes along with them, while epistemic knowledge entails, for example, understanding why such methods are used.

In this context, one open question some studies have considered is how someone's knowledge about scientific processes might affect their interpretation of scientific uncertainty. In a large survey study, people who had higher knowledge about scientific methods were also more aware of uncertainty within science (Retzbach, Otto, \& Maier, 2016). In a qualitative study, participants accepted uncertainty if they also believed that uncertainty is intrinsic to science (Maxim \& Mansier, 2014). Similarly, in an experimental study, Kimmerle, Flemming, Feinkohl, and Cress (2015) found that participants who believed science to be uncertain tended to perceive higher scientific uncertainty in news reports. Along these lines, when Rabinovich and Morton (2012) encouraged participants to believe that science is a debate (vs. the search for a single truth), they were more motivated to behave sustainably. Further, Flemming, Kimmerle, Cress, and Sinatra (2020) were able to reduce the negative effects of scientific uncertainty on ratings of credibility by introducing participants to the role of scientific uncertainty in research using a refutation text. All these results are in line with the theoretical and empirically tested idea (Gauchat, 2011) that the general public's trust in science is related to believing that scientific processes ('the scientific method') culturally demarcate scientific knowledge from other types of knowledge.

Given the above findings, we assumed for our studies that if, along with a text discussing the scientific uncertainties of a particular issue, participants were also given information about the direct source of the uncertaintynamely, the associated scientific research methodsthis might make them more trustful and allow them to more easily make decisions. For example, it is possible that when participants are informed that scientific models are based on data and are continuously improved, 
they may be able to explain and partially resolve modeling uncertainty.

\section{Study 1}

Overall, the empirical research is inconclusive on how communicated uncertainty affects laypeople (van der Bles et al., 2019). Specifically, it is still unclear how communicated scientific uncertainty affects laypeople's judgments of the credibility of messages and their overall trust in scientists and scientific disciplines. To explore these research questions further, we designed an experimental study with a two-factorial design. Scientific uncertainty was varied by introducing scientific uncertainty in a fictitious newspaper article on how climate change affects ocean life. This text was presented to two experimental groups (scientific uncertainty conditions). The other two groups (non-scientific uncertainty conditions) read the same text, but the information was presented as certain (e.g., 'later studies found similar results'). Furthermore, in order to enhance participants' abilities to evaluate scientific uncertainty, we aimed to activate participants' relevant knowledge about sources of uncertainty. Hence, empirical research methods (which were directly applicable to the uncertainty mentioned in the news article text) were presented to two groups (empirical research methods conditions) before they read the newspaper article with/without scientific uncertainty; the other two groups (non-empirical research methods conditions) read texts on media coverage about climate change.

We investigated whether being exposed to scientific uncertainty (scientific uncertainty conditions) and/or learning about empirical research methods (empirical research methods conditions) affected participants' (1) assessment of the issue uncertainty, (2) perception of the article's credibility, (3) trust in the scientists' assertions and trust in climate science, and (4) ease with which they were able to reach a personal decision on the issue. We expected that communicating scientific uncertainty to participants would increase their perception of the issue uncertainty and decrease their ease of making a decision but also increase their trust in scientists (e.g., Jensen, 2008; Rabinovich \& Morton, 2012) and in climate science in general:

$\mathrm{H} 1$ : In the scientific uncertainty conditions, ratings of issue uncertainty are higher, and ratings of decision-making ease are lower, compared to the nonscientific uncertainty conditions (main effect).

$\mathrm{H} 2$ : In the scientific uncertainty conditions, ratings of information credibility and trust in climate scientists and climate science are higher, compared to the nonscientific uncertainty conditions (main effect).

We furthermore expected that providing participants with information about empirical research methods might enhance their trust in climate scientists and in climate science, as similar research found that introducing participants to the unavoidability of uncertainty in science increased credibility and trust ratings (e.g., Flemming et al., 2020).

H3: In the empirical research methods conditions, ratings of trust in climate scientists and climate science are higher, compared to the non-empirical research methods conditions (main effect).

H4: In the empirical research methods conditions, ratings of decision-making ease are higher, especially for the scientific uncertainty condition (interaction effect).

\subsection{Methods}

For experimental materials and measures, see the Supplementary File. This study was preregistered (Hendriks, Ilse, \& Jucks, 2017). We conducted a power analysis to calculate the sample size needed to detect a small effect of partial eta square of .01 with a power of .95 and an alpha of .05, using $\mathrm{G}^{*}$ power (Faul, Erdfelder, Buchner, \& Lang, 2009). The determined sample size was 175 .

\subsubsection{Sample}

We recruited university students via open Facebook groups and a university newsletter, resulting in $N=286$ participants who finished the questionnaire and consented to data usage. After excluding those who had studied at an (applied) university for more than two semesters and those who used a mobile phone to complete the questionnaire, we were left with $N=207$ participants. Those participants were between 18 and 41 years of age $(M=20.34 ; S D=2.56)$, and $63.8 \%$ were female, $33.8 \%$ male, and $2.4 \%$ chose not to disclose their gender. Most $(60.4 \%)$ majored in social sciences, economics, or law; $13.0 \%$ in science, technology, engineering e mathematics; $11.6 \%$ in the arts; the remaining $25 \%$ in health, nutrition or sports. One participant had not studied at a college/university.

\subsubsection{Procedure and Measures}

After giving information about participating in the study, we presented participants with demographical questions (age, gender, education). Next, we had them read the two texts: First, participants read about research methods (experimental methods and mathematical models) or media coverage on climate change (empirical research methods versus non-empirical research methods conditions), and then they read about ocean acidification with/without uncertainty (resulting from comparing lab and field experiments, from making generalizations, and from making predictions from mathematical models; scientific uncertainty versus non-scientific uncertainty con- 
ditions). The experimental groups were randomly selected by the survey software, leaving $n=51$ in the 'empirical research methods/scientific uncertainty' condition, $n=50$ in the 'empirical research methods/nonscientific uncertainty' condition, $n=56$ in the 'nonempirical research methods/scientific uncertainty condition,' and $n=50$ participants in the 'non-empirical research methods/non-scientific uncertainty' condition.

Uncertainty assessment was then measured with four items, such as 'Climate science has not yet sufficiently researched all impacts of climate change on ocean life.' Credibility of information (three items as in Appelman \& Sundar, 2016), trust in assertions by climate scientists (three items, e.g., 'I trust statements of climate scientists about the impact of climate change on the oceans'), and trust in climate science (three items related to expertise, integrity and benevolence, e.g., 'I trust climate science, because I believe that climate scientists are experts in their field'; adapted from Wissenschaft im Dialog, 2018) were measured on 5-point Likert scales ( 1 'I do not agree' to 5 'I agree very much'). A further measure on epistemic aims is not reported in this article. We next presented several statements of climate-friendly behavior, asking participants whether they would do these in the next month (e.g., 'use a bike, walk, or use public transport instead of taking the car,' using Likert scales from 1 'not likely' to 5 'likely'). Next, we measured participants' ease of decision-making to partake in climate-friendly behavior by asking them to choose three options from the list and indicate how ready they were to act on these for a month (from 1 'not ready' to 5 'ready'). Certainty in this decision was then measured with the two subscales uncertainty and decision effectiveness of the Decisional Conflict Scale (item 10-16; Buchholz, Hölzel, Kriston, Simon, \& Härter, 2011). We also asked what could hinder participants from carrying out these behaviors in the next month (four items, such as 'lack of finances'; one optional open-ended item).

Finally, we explained that the texts were fictional and possibly simplified and asked for participants' consent to use their data.

\subsection{Statistical Analyses}

Using SPSS 25, we conducted analyses of variance (ANOVA) with two factors: empirical research methods and scientific uncertainty. For the scales that were expected to be positively interrelated, we conducted multivariate analyses of variance (MANOVA) to inspect general effects and limit the accumulation of Type I errors, and we followed up with ANOVA for each of the respective scales and simple effects analyses. For the full report of results, see the Supplementary File.

\subsection{Results}

As expected, the degree to which participants perceived issue uncertainty was higher when uncertainty was in- cluded in the text $(\mathrm{H} 1)$ : The factor scientific uncertainty $\left(p<.001, \eta_{p}^{2}=.20\right)$ was significant, while empirical research methods was not $(p=.123$; neither was the interaction, $p=.281$ ).

The texts were perceived to be of similar credibility (empirical research methods, $p=.516$; scientific uncertainty: $p=.580$; interaction: $p=.563$ ). A MANOVA showed an interaction effect for empirical research methods and scientific uncertainty on participants' trust judgments ( $\left.p=.007, \eta_{p}^{2}=.05\right)$, but there was no evidence for a main effect of either empirical research methods ( $p=.815)$ or scientific uncertainty $(p=.117)$. Separate univariate ANOVAs only showed an interaction effect for trust in the assertions made by climate scientists ( $\left.p=.015, \eta_{p}^{2}=.03\right)$, which we followed up by simple effects analyses (Bonferroni corrected). These indicated that trust in assertions ratings were significantly lower in the 'empirical research methods/scientific uncertainty' condition $(M=3.78, S D=0.66)$ than in the 'nonempirical research methods/scientific uncertainty' condition $(M=4.06, S D=0.67 ; F(1,203)=4.86, p=.029)$ and in the 'empirical research methods/non-scientific uncertainty' condition $(M=4.11, S D=0.54 ; F(1,203)=6.57$, $p=.011)$. The other two comparisons of experimental groups did not reach significance (see Supplementary File). In sum, these results do not support $\mathrm{H} 2$ and directly contradict $\mathrm{H} 3$.

Regarding the decision (committing to climatefriendly behavior), no difference between groups could be observed (empirical research methods: $p=.607$; scientific uncertainty: $p=.538$; interaction: $p=.527$ ). In contrast to $\mathrm{H} 4$, participants' ease of decision-making did not differ between the experimental conditions, as shown by a MANOVA with both scales as dependent variables (empirical research methods: $p=.801$; scientific uncertainty: $p=.431$; interaction: $p=.183$ ).

\subsection{Intermediate Discussion of Study 1}

When scientific uncertainty was communicated in the news article (about the effect of ocean acidification on ocean life), participants perceived higher issue uncertainty (confirming $\mathrm{H} 1$ ). However, this experimental variation did not lead participants to rate the credibility of the information or their trust in climate science differently (not supporting $\mathrm{H} 2$ ). When participants were given information about empirical research methods in addition to the article entailing scientific uncertainty, they gave lower ratings for trust in climate scientists' assertions, as compared to experimental conditions in which participants only read the news containing scientific uncertainty but did not read about research processes, or when participants did read about the research processes and did read the news article, but the news article contained no scientific uncertainty (contradicting H3). There was no evidence for an effect of the experimental variation on participants' decision to behave in a climate-friendly way, nor on the ease 
with which this decision was made (not supporting $\mathrm{H} 1$ in this regard).

These findings contradict our expectation that giving participants information about the research methods would ease their interpretation of uncertainty and, thus, enhance their trust in climate scientists' assertions and in climate science generally. Possibly, as the text explaining the empirical research methods included several sources of uncertainty (measuring, sampling, and modeling), participants may have been more skeptical towards the certainty on which climate scientists' assertions rest in general.

\section{Study 2}

We tested this interpretation in study 2 , in which we varied the text that had, in study 1 , explained the empirical research methods. In study 2, participants received one of two versions of this text, which described two separate research processes, namely the empirical research methods (as in study 1 ) and the role of expert consensus in science (described in detail below). Regardless of the research process being considered, in the study 2 variations of this text, we either framed uncertainty in an 'expected' way, in which we emphasized that the scientific process is intended to increase certainty, or we framed uncertainty in an 'exaggerated' way, where we highlighted the uncertainty that follows from scientific processes. That is, we tested whether the framing of scientific uncertainty-either as something inherent to science or as something that fundamentally challenges making reliable conclusions from evidenceaffected participants' ratings of the article's credibility, ratings about trust, and their decision-making surrounding the issue. In all conditions of study 2 , the news article text presented the issue (the effect of ocean acidification on ocean life) as scientifically uncertain (as in study 1's scientific uncertainty conditions).

As briefly mentioned above, in addition to the two conditions of framing uncertainty ('expected' vs. 'exaggerated'), we varied the text on research processes to describe two different types of process, where one condition described the empirical research methods (as in study 1) and the other described the role of experts finding a consensus in science. Especially around the issue of climate change, expert consensus finding is argued to be a central scientific process for achieving certainty (Oreskes, 2007). Hence, highlighting processes of consensus finding and quality checking among experts (e.g., peer review) might help people understand that when scientific uncertainty exists in a scientific field, it is not because pertinent scientific experts cannot be trusted (as might be inferred from the results of study 1 ). Hence, regarding the two conditions for consensus finding, in one we framed uncertainty in an 'expected' way, where we emphasized that expert consensus plays a pivotal role in generating reliable scientific knowledge, and in the other condition we framed uncertainty in an 'exaggerated' way, where we highlighted the uncertainty that arises from expert disagreement. Similar variations were made for the two conditions concerning empirical research methods: In one condition, we framed uncertainty in an 'expected' way, in which we emphasized that empirical scientific methods are intended to increase certainty, whereas in the other condition we framed uncertainty in an 'exaggerated' way (e.g., stating that lab experiments do not allow for making conclusions about the real world). Our hypotheses for study 2 are as follows:

H5: When uncertainty is framed in an exaggerated way, participants give higher ratings for issue uncertainty and have a lower ease of decision-making compared to when uncertainty is framed as being expected (i.e., as part of the scientific process; main effect).

H6: When uncertainty is framed in an exaggerated way, participants give lower ratings for information credibility and trust in climate scientists and climate science compared to when uncertainty is framed as being expected (main effect).

Furthermore, to assess individual differences between participants, we included a measure for epistemic style (Elphinstone, Farrugia, Critchley, \& Eigenberger, 2014). This inventory measures people's preferences for information processing and problem solving: One scale reflects preference for intellective style reasoning (e.g., by deep reflection on problems), and the other a default style reasoning (e.g., by finding quick solutions). This reflects a two-system approach for dealing with uncertainty that has been assumed to be useful for examining the role of scientific uncertainty in public communication of science (Patt \& Weber, 2014). Since participants' epistemic style might influence their reasoning about scientific processes and scientific uncertainty, this may, in turn, also affect their judgments about credibility and trust. Hence, we investigated (as research question of the study) whether participants' epistemic style influenced their ratings on all dependent variables that followed the experimental manipulations (covariation effect).

\subsection{Methods}

The experimental materials can be found in the Supplementary File. This study was approved by the authors' university's ethics commission (2018-21-FH) prior to data collection.

\subsubsection{Sample}

We recruited participants via a university newsletter, resulting in $N=170$ who finished the questionnaire and consented to data use (mobile phone users were not permitted to take part, but were asked to use a lap- 
top/desktop computer). After excluding those who had studied at an (applied) university for more than two semesters and those who were suspected to or had selfreported as participating in the previous study, we were left with $N=129$ participants. Those participants were between 18 and 33 years of age $(M=20.73 ; S D=2.65$, the entry ' 11 ' was recoded as missing), and $56.6 \%$ were female, $39.5 \%$ male, and $3.9 \%$ chose not to disclose their gender. Most (42.6\%) majored in social sciences, economics, or law; $34.1 \%$ in science, technology, engineering e mathematics; $17.8 \%$ in the arts; the remaining $4.9 \%$ in health, nutrition or sports.

\subsubsection{Procedure and Measures}

The procedure was similar to study 1 . After presenting information about participation, we asked participants demographic questions (age, gender, education). To increase relevance, students were given a cover story, namely that participants had to write an argumentation in a class (e.g., at university), and for that, had to read the two texts, where one was introduced as a background text and the other as a newspaper article (no specific source references were given).

The two texts were as follows: First, participants were to read one of four versions of the background text on research processes. In the condition 'empirical research methods/expected uncertainty framing,' participants received a background text that emphasized how experimental studies and modeling are used to achieve reliable knowledge in climate science $(n=40$; similar to the empirical research methods conditions from study 1 ). In the condition 'expert consensus/expected uncertainty framing,' the background text described how experts in climate science reach consensus $(n=31)$. In the condition 'empirical research methods/exaggerated uncertainty framing' $(n=32)$ and the condition 'expert consensus/exaggerated uncertainty framing' $(n=26)$, the background texts described scientific processes by evoking the uncertainty around evidence or highlighting the disagreement between experts, respectively. All experimental groups then read the same news article on ocean acidification, similar to the scientific uncertainty text from study 1 . The experimental groups were randomly selected by the survey software.

As in study 1 , we measured participants' assessment of uncertainty, their perception of information credibility, and their trust in climate scientists/climate science. A questionnaire on epistemic aims, and another on strategies participants use to deal with an informational problem are not reported.

Regarding decision-making, participants were asked to make a different decision than in study 1. Imagining they had to write an argumentation for their class, they were asked which claim they would support: 'Impacts of climate change on ocean [life] are...' (see the Supplementary File for original item) followed by the options from 1 'not at all grave' to 5 'very grave.' Two fur- ther items (see the Supplementary File) measured participants' attitudes toward climate science. Then, epistemic style was measured with the two scales (intellective style, default style) of the Epistemic Preference IndicatorRevised (EPI-R; Elphinstone et al., 2014) on Likert scales from 1 'do not agree at all' to 5 'very much agree'). For neither scale was a difference between groups observed (see the Supplementary File).

Finally, we explained that the texts were fictional and possibly simplified, and then we asked whether participants were familiar with the study materials, whether they had seen news reports on predatory journals, and whether participants would give us consent to use their data.

\subsection{Statistical Analyses}

Using SPSS 25, we conducted analyses of covariance (ANCOVA) with two factors: the type of research processes (TRP: 'empirical research methods' and 'expert consensus') and uncertainty framing (UF: 'expected' and 'exaggerated'), using as covariates both scales of the EPI-R (centered by subtracting the variable sample mean; Schneider, Avivi-Reich, \& Mozuraitis, 2015). Again, we conducted multivariate analyses of covariance (MANCOVA) for positively interrelated scales. See the Supplementary File for full results.

\subsection{Results}

Contrary to our H5, we found that the degree to which participants perceived uncertainty was neither a result of experimental variation nor influenced by the covariates (TRP, $p=.750 ; \mathrm{UF}, p=.868$; interaction $p=.331$; EPI-R default style, $p=.309$; EPI-R intellective style, $p=.144$ ).

Regarding $\mathrm{H} 6$, results showed that all texts were perceived to be of similar credibility (TRP, $p=.339$; $\mathrm{UF}, p=.506$; interaction $p=.350$; EPI-R default style, $p=.395$; EPI-R intellective style, $p=.897$ ). A MANOVA showed that the experimental variation did not impact participants' trust ratings (TRP, $p=.503$; UF, $p=.961$; interaction $p=.171)$. However, regarding RQ1, while the EPI-R sub-scale intellective style did reach significance as a covariate $\left(p=.010, \eta_{p}^{2}=.07\right)$, default style did not $(p=.158)$. Separate univariate ANOVAs showed that intellective style did covary significantly with both trust in assertions by climate scientists $\left(p=.008, \eta_{p}^{2}=.06\right)$ and trust in climate science $\left(p=.004, \eta_{p}^{2}=.06\right)$.

There was no evidence of an effect of experimental variations on participants' decisions (on the gravity of climate change effects on ocean life) (TRP, $p=.934$; UF, $p=.932$; i n-teraction, $p=.866)$. The EPI-R sub-scale intellective style was significant as covariate $(p=.006$, $\left.\eta_{p}^{2}=.06\right)$, but not default style $(p=.906)$. Contradicting H5, a MANOVA for ease of decision-making showed no effects as a result of the experimental variation, but ease of decision-making did co-vary with intellective style (TRP, $p=.482$; UF, $p=.154$; interaction, $p=.073$; EPI-R in- 
tellective style, $p=.036, \eta_{p}^{2}=.05$; EPI-R default style, $p=.120)$. Separate ANCOVAs revealed that the intellective style covariate affected ratings on both scales of the Decisional Conflict Scale (measuring ease of decision making), namely the certainty $\left(p=.043, \eta_{p}^{2}=.03\right)$ and the effectiveness of the decision $\left(p=.010, \eta_{p}^{2}=.05\right)$. We do not interpret further effects in the separate ANCOVAs, because they were not significant by MANOVA.

\subsection{Intermediate Discussion of Study 2}

In study 2, we did not find any significant effects that were due to experimental variations. That is, there was no evidence that either ascribing the source of uncertainty to empirical research methods vs. expert disagreement, or framing uncertainty as being expected vs. being exaggerated affected participants' ratings of perceived uncertainty and ease of decision-making (counter to H5), or their assessments of information credibility and trust (counter to H6). However (regarding the study's research question), we found that having an intellective epistemic style-an appreciation for dealing with complex issues and engaging in problem solving-was a covariate for participants' trust in the assertions of climate scientists and their trust in climate science, as well as for the decision (claim support) and ease of decision-making. Thus, a preference for deep reflection about such issues may be even more relevant for trust in science and making decisions about scientific issues than is being exposed to messages that attack the scientific processes underlying uncertainty in climate change information.

\section{General Discussion}

The results of study 1 showed that while the presence of scientific uncertainty in a text on ocean acidification led participants to more highly rate the uncertainty of the issue, it did not cause participants to have more uncertainty when making a decision related to the issue. Similarly, this experimental variation did not cause participants to give higher rankings on information credibility, to have greater trust in the assertions made by climate scientists, or to have greater trust in climate science. On the contrary, when participants read a text describing empirical research methods prior to reading the article containing scientific uncertainty, they had even less trust in the assertions made by climate scientists. In contrast to what we expected from previous research (e.g., Flemming et al., 2020), our study found no evidence that having participants read texts describing the role of uncertainty in scientific research would ease how they later interpreted the scientific uncertainty presented within the article.

In study 2, we tested whether this effect could be attributed to the text on empirical research methods, which introduced several sources of uncertainty and thus could have resulted in the impression that scientific processes in climate science are unreliable. However, the re- sults of study 2 showed that this seems not to have been the case: There was no evidence that framing scientific processes (either empirical research methods or expert consensus) as the main source of scientific uncertainty would negatively impact participants' trust in climate scientists' assertions or their trust in climate science. However, the extent to which participants rated their attitude to approaching science-based problems as reflecting an intellective epistemic style did influence their trust judgments and their decision-making. Hence, how people resolve scientific uncertainty might depend more on individual information processing preferences than on how scientific uncertainty is framed in news articles.

In sum, our studies indicate that while participants did perceive the uncertainty introduced in news articles, this did not affect their decision-making, and it only slightly influenced their trust: Having information on scientific processes (empirical research methods) in combination with reading scientific uncertainty in the news article did result in participants having slightly lower trust in climate scientists' assertions (e.g., to make meaningful claims about the issue). However, there was no evidence that this would affect participants' overall trust in climate science, and neither did framing the scientific uncertainty in an exaggerated way (both regarding empirical research processes and expert disagreement). This could be due to participants' prior knowledge about and their attitude toward uncertainty in scientific information: Participants might have expected scientific results to be rather uncertain (not due to the text we introduced with this aim), thus making them unreceptive toward appeals to (sources of) scientific uncertainty.

The effects of scientific uncertainty on trust and behavioral intentions are worthwhile to study, as past studies have differed in their measured concepts (e.g., trust, emotion, behavioral intentions), and focus (e.g., uncertainty of statistical estimates vs. generalizability of experiments; see van der Bles et al., 2019, 2020). In the present work, we investigated how scientific uncertainty is interpreted when people are reminded that scientific processes act both as the source and as a resolution for uncertainty. However, the texts we used in the experiments might have been too complex or not relevant enough for participants. Further, each text referred to several sources of scientific uncertainty. We deemed this necessary to remind participants that there is fundamental scientific uncertainty in climate science but also that research processes are being continuously optimized to approximate 'truth.' Further research should address the field's yet fragmented understanding on the communication of uncertainty, making precise distinctions between different types and sources of scientific uncertainty. As such, further studies should examine consequences of different sources and types of scientific uncertainty on trust, emotion, and behavior.

Trust is a complex concept, as it can be directed at the source of knowledge, experts, or science in general. Our studies addressed only trust in climate science re- 
searchers and trust in the discipline of climate science, for which we used two small scales. While in our studies both scales show acceptable internal consistency (see the Supplementary File), they should be formally tested for reliability and validity in a larger sample. Further studies should use more elaborate trust scales to further examine the effects of scientific uncertainty (in its different forms) on trust.

Another limitation of our work is that we only questioned university students. We aimed for a sample that had little formally acquired procedural knowledge, such that we excluded participants that had already completed their first year of university education. The studies should be replicated with a more diverse sample, as students could be generally aware of scientific uncertainty and might have an accepting attitude toward science. However, our studies suggest that in a population of students who do not yet possess university-level scientific literacy, adversarial information about scientific uncertainty and its sources might have little to no effect.

\section{Conclusion}

Our studies add to the literature on the public assessment of scientific uncertainty, which has produced conflicting results (van der Bles et al., 2019), and they are relevant to understanding how readers perceive and interpret scientific uncertainty in digital news media, for example when it is directed at weakening their trust in science. As a consequence of uncertainty being used to provoke doubt about science, uncertainty in climate change communication has often been linked with adverse responses by recipients (Lewandowsky et al., 2015). Strategic appeals regarding science's inability to achieve reliable results might be especially prevalent in attacks on climate science in digital media such as blogs (Elgesem et al., 2015; Mercer, 2018), but also in the context of anti-vaccination, advocates might use scientific evidence in digital media outlets to persuade their readers (e.g., Moran, Lucas, Everhart, Morgan, \& Prickett, 2016; Schalkwyk, 2019). Our studies show that while participants' trust judgments were slightly affected by addressed scientific uncertainty in the two texts (study 1), an exaggeration of scientific uncertainty originating from empirical research or expert consensus did not lead to lower trust judgments than when uncertainty was presented as being expected (study 2). However, how scientific uncertainty can be communicated to a more general public should be carefully considered (Corner, Lewandowsky, Phillips, \& Roberts, 2015; Druckman, 2015).

Especially in user comments, scientific uncertainty and the credibility of scientific research might be critically addressed (Lörcher \& Taddicken, 2017). In a study investigating attacks on science in user comments (added to social media entries introducing a scientific study), expert user comments targeting thematic complexity were perceived to be more credible and reduced participants' agreement with a scientific claim, in comparison with, for example, comments targeting researcher competence (Gierth \& Bromme, 2020). Similarly, 'incivility' in user comments might polarize readers' attitudes on a scientific topic (Anderson, Brossard, Scheufele, Xenos, \& Ladwig, 2014), and negative user comments on a blog post may sour readers' attitudes toward a scientific topic, both when comments use scientific arguments or subjective opinions (Winter \& Krämer, 2016). In sum, the mere presence of dissenting user comments might be effective in reducing reader's trust in scientific results. This means that in digital media, science communicators should not only carefully consider the extent and framing of their communication of uncertainty inherent in scientific results, but they should also be attentive of whether user comments challenge science by pointing to scientific uncertainty. While our studies did not find that giving readers information about scientific processes effectively reduced negative impacts of uncertainty on trust, this and other communicative strategies to protect against the utilization of scientific uncertainty to attack science should be further investigated.

\section{Acknowledgments}

We thank Teresa Ilse, who collected the data from study 1 as part of her master's thesis. The data were completely reanalyzed for this article. We cordially thank Celeste Brennecka for native speaker advice.

\section{Conflict of Interests}

The authors have no conflicting interests to declare.

\section{Supplementary Material}

Supplementary material for this article is available online in the format provided by the author (unedited).

\section{References}

Anderson, A. A., Brossard, D., Scheufele, D. A., Xenos, M. A., \& Ladwig, P. (2014). The "nasty effect": Online incivility and risk perceptions of emerging technologies. Journal of Computer-Mediated Communication, 19(3), 373-387. https://doi.org/10.1111/jcc4.12009

Appelman, A., \& Sundar, S. S. (2016). Measuring message credibility. Journalism \& Mass Communication Quarterly, 93(1), 59-79. https://doi.org/10.1177/ 1077699015606057

Bromme, R., \& Goldman, S. R. (2014). The public's bounded understanding of science. Educational Psychologist, 49(2), 59-69. https://doi.org/10.1080/ 00461520.2014 .921572

Broomell, S. B., \& Kane, P. B. (2017). Public perception and communication of scientific uncertainty. Journal of Experimental Psychology: General, 146(2), 286-304. https://doi.org/http://dx.doi.org/ $10.1037 / x g e 0000260$ 
Buchholz, A., Hölzel, L., Kriston, L., Simon, D., \& Härter, M. (2011). Die Decisional Conflict Scale in deutscher Sprache (Decisional Conflict Scale-D): Dimensionale Struktur in einer Stichprobe von Hausarztpatienten [German-language version of Decisional Conflict Scale (Decisional Conflict Scale-D): Dimensional structure in a sample of family physician patients]. Klinische Diagnostik und Evaluation, 4, 15-30.

Corner, A., Lewandowsky, S., Phillips, M., \& Roberts, O. (2015). The uncertainty handbook: A practical guide for climate change communicators. Bristol: University of Bristol.

Druckman, J. N. (2015). Communicating policy-relevant science. PS: Political Science and Politics, 48(S1), 58-69. https://doi.org/10.1017/S10490965150004 38

Dunwoody, S., Hendriks, F., Massarani, L., \& Peters, H. P. (2018). How journalists deal with scientific uncertainty and what that means for the audience. Paper presented at the 15th International Public Communication of Science and Technology Conference, Dunedin, New Zealand.

Elgesem, D., Steskal, L., \& Diakopoulos, N. (2015). Structure and content of the discourse on climate change in the blogosphere: The big picture. Environmental Communication, 9(2), 169-188. https://doi.org/ 10.1080/17524032.2014.983536

Elphinstone, B., Farrugia, M., Critchley, C., \& Eigenberger, M. E. (2014). Examining the measurement of epistemic style: The development and validation of the Epistemic Preference Indicator-Revised. Personality and Individual Differences, 58, 101-105. https://doi. org/10.1016/j.paid.2013.10.013

Faul, F., Erdfelder, E., Buchner, A., \& Lang, A. G. (2009). Statistical power analyses using G*Power 3.1: Tests for correlation and regression analyses. Behavior Research Methods, 41(4), 1149-1160. https://doi.org/ 10.3758/BRM.41.4.1149

Flemming, D., Kimmerle, J., Cress, U., \& Sinatra, G. M. (2020). Research is tentative, but that's okay: Overcoming misconceptions about scientific tentativeness through refutation texts. Discourse Processes, 57(1), 17-35. https://doi.org/10.1080/0163853X. 2019.1629805

Freudenburg, W. R., Gramling, R., \& Davidson, D. J. (2008). Scientific certainty argumentation methods (SCAMs): Science and the politics of doubt. Sociological Inquiry, 78(1), 2-38. https://doi.org/10.1111/ j.1475-682X.2008.00219.x

Friedman, S. M., Dunwoody, S., \& Rogers, C. L. (2012). Communicating uncertainty. Abingdon: Routledge. https://doi.org/10.4324/9781410601360

Gauchat, G. (2011). The cultural authority of science: Public trust and acceptance of organized science. Public Understanding of Science, 20(6), 751-770. https://doi.org/10.1177/0963662510365246

Gierth, L., \& Bromme, R. (2020). Attacking science on social media: How user comments affect per- ceived trustworthiness and credibility. Public Understanding of Science, 29(2), 230-247. https://doi.org/ $10.1177 / 0963662519889275$

Gustafson, A., \& Rice, R. E. (2019). The effects of uncertainty frames in three science communication topics. Science Communication, 41(6), 679-706. https:// doi.org/10.1177/1075547019870811

Han, P. K. J., Moser, R. P., \& Klein, W. M. P. (2007). Perceived ambiguity about cancer prevention recommendations: Associations with cancer-related perceptions and behaviours in a US population survey. Health Expectations, 10(4), 321-336. https://doi. org/10.1111/j.1369-7625.2007.00456.x

Hendriks, F., Ilse, T., \& Jucks, R. (2017). How scientific process knowledge helps laypeople to deal with uncertainty. Philadelphia, PA: University of Pennsilvania Wharton Credibility Lab. Retrieved from https:// aspredicted.org/tt2qu.pdf

Hendriks, F., \& Kienhues, D. (2019). Science understanding between scientific literacy and trust: Contributions from psychological and educational research. In A. Leßmöllmann, M. Dascal, \& T. Gloning (Eds.), Science communication (pp. 29-50). Berlin and Boston, MA: De Gruyter.

Hendriks, F., Kienhues, D., \& Bromme, R. (2015). Measuring laypeople's trust in experts in a digital age: The Muenster Epistemic Trustworthiness Inventory (METI). PLOS ONE, 10(10), 1-20. https://doi.org/ 10.1371/journal.pone.0139309

Jensen, J. D. (2008). Scientific uncertainty in news coverage of cancer research: Effects of hedging on scientists' and journalists' credibility. Human Communication Research, 34(3), 347-369. https://doi.org/ 10.1111/j.1468-2958.2008.00324.x

Jensen, J. D., Carcioppolo, N., King, A. J., Bernat, J. K., Davis, L., Yale, R., \& Smith, J. (2011). Including limitations in news coverage of cancer research: Effects of news hedging on fatalism, medical skepticism, patient trust, and backlash. Journal of Health Communication, 16(5), 486-503. https://doi.org/10.1080/ 10810730.2010.546491

Kimmerle, J., Flemming, D., Feinkohl, I., \& Cress, U. (2015). How laypeople understand the tentativeness of medical research news in the media: An experimental study on the perception of information about deep brain stimulation. Science Communication, 37(2), 173-189. https://doi.org/10.1177/ 1075547014556541

Lewandowsky, S., Ballard, T., \& Pancost, R. D. (2015). Uncertainty as knowledge. Philosophical Transactions of the Royal Society A: Mathematical, Physical and Engineering Sciences, 373(2055). https://doi.org/ 10.1098/rsta.2014.0462

Lörcher, I., \& Taddicken, M. (2017). Discussing climate change online: Topics and perceptions in online climate change communication in different online public arenas. Journal of Science Communication, 16(2), 1-21. https://doi.org/10.22323/2.16020203 
Matthews, P. (2015). Why are people skeptical about climate change? Some insights from blog comments. Environmental Communication, 9(2), 153-168. https://doi.org/10.1080/17524032.2014.999694

Maxim, L., \& Mansier, P. (2014). How is scientific credibility affected by communicating uncertainty? The case of endocrine disrupter effects on male fertility. Human and Ecological Risk Assessment: An International Journal, 20(1), 201-223. https://doi.org/ 10.1080/10807039.2012.719387

Mayweg-Paus, E., \& Jucks, R. (2015). Evident or doubtful? How lexical hints in written information influence laypersons understanding of influenza. Psychology, Health and Medicine, 20(8), 989-996. https:// doi.org/10.1080/13548506.2014.986139

Mercer, D. (2018). Why Popper can't resolve the debate over global warming: Problems with the uses of philosophy of science in the media and public framing of the science of global warming. Public Understanding of Science, 27(2), 139-152. https://doi.org/10.1177/ 0963662516645040

Moran, M. B., Lucas, M., Everhart, K., Morgan, A., \& Prickett, E. (2016). What makes anti-vaccine websites persuasive? A content analysis of techniques used by anti-vaccine websites to engender antivaccine sentiment. Journal of Communication in Healthcare, 9(3), 151-163. https://doi.org/10.1080/ 17538068.2016.1235531

National Academies of Sciences, Engineering, and Medicine. (2017). Communicating science effectively: A research agenda. Washington, DC: National Academies Press.

Oreskes, N. (2007). The scientific consensus on climate change: How do we know we're not wrong. In J. F. C. DiMento \& P. Doughman (Eds.), Climate change: What it means for us, our children, and our grandchildren (pp. 65-99). Cambridge, MA: MIT Press.

Oreskes, N. (2015). The fact of uncertainty, the uncertainty of facts and the cultural resonance of doubt. Philosophical Transactions of the Royal Society, 373(2055). https://doi.org/10.1098/rsta.2014.0455

Oreskes, N., \& Conway, E. M. (2011). Merchants of doubt: How a handful of scientists obscured the truth on issues from tobacco smoke to global warming. New York, NY: Bloomsbury Press.

Organisation for Economic Co-operation and Development. (2017). PISA 2015 assessment and analytical framework. Paris: OECD Publishing.

Patt, A. G., \& Weber, E. U. (2014). Perceptions and communication strategies for the many uncertainties relevant for climate policy. Wiley Interdisciplinary Reviews: Climate Change, 5(2), 219-232. https://doi. org/10.1002/wcc.259

Peters, H. P., \& Dunwoody, S. (2016). Scientific uncertainty in media content: Introduction to this special issue. Public Understanding of Science, 25(8), 1009-1013. https://doi.org/10.1177/09636625166 74649
Rabinovich, A., \& Morton, T. A. (2012). Unquestioned answers or unanswered questions: beliefs about science guide responses to uncertainty in climate change risk communication. Risk Analysis, 32(6), 992-1002. https://doi.org/10.1111/j.1539-6924. 2012.01771.x

Ratcliff, C. L., Jensen, J. D., Christy, K., Crossley, K., \& Krakow, M. (2018). News coverage of cancer research: Does disclosure of scientific uncertainty enhance credibility? In H. D. O'Hair (Ed.), Risk and health communication in an evolving media environment (pp. 156-175). New York, NY: Routledge.

Retzbach, J., Otto, L., \& Maier, M. (2016). Measuring the perceived uncertainty of scientific evidence and its relationship to engagement with science. Public Understanding of Science, 25(6), 638-655. https://doi. org/10.1177/0963662515575253

Schäfer, M. S. (2016). Mediated trust in science: Concept, measurement and perspectives for the 'science of science communication.' Journal of Science Communication, 15(5), 1-7. https://doi.org/10.22323/2. 15050302

Schalkwyk, F. v. (2019). The amplification of uncertainty: The use of science in the social media by the antivaccination movement. In P. Weingart, M. Joubert, \& B. Falade (Eds.), Science communication in South Africa: Reflections on current issues (pp. 170-212). Cape City: African Minds.

Schneider, B. A., Avivi-Reich, M., \& Mozuraitis, M. (2015). A cautionary note on the use of the Analysis of Covariance (ANCOVA) in classification designs with and without within-subject factors. Frontiers in Psychology. https://doi.org/10.3389/fpsyg.2015.00474

Sharman, A. (2014). Mapping the climate sceptical blogosphere. Global Environmental Change, 26(1), 159-170. https://doi.org/10.1016/j.gloenvcha.2014. 03.003

Sperber, D., Clément, F., Heintz, C., Mascaro, O., Mercier, H., Origgi, G., \& Wilson, D. (2010). Epistemic vigilance. Mind and Language, 25(4), 359-393. https://doi.org/ 10.1111/j.1468-0017.2010.01394.x

Thiebach, M., Mayweg-Paus, E., \& Jucks, R. (2015). “Probably true" says the expert: How two types of lexical hedges influence students' evaluation of scientificness. European Journal of Psychology of Education, 30(3), 369-384. https://doi.org/10.1007/ s10212-014-0243-4

van der Bles, A. M., van der Linden, S., Freeman, A. L. J., Mitchell, J., Galvao, A. B., Zaval, L., \& Spiegelhalter, D. J. (2019). Communicating uncertainty about facts, numbers and science. Royal Society Open Science, 6, 1-42. https://doi.org/10.1098/rsos.181870

van der Bles, A. M., van der Linden, S., Freeman, A. L. J., \& Spiegelhalter, D. J. (2020). The effects of communicating uncertainty on public trust in facts and numbers. Proceedings of the National Academy of Sciences. https://doi.org/10.1073/pnas.1913678117 Walker, V. R. (1991). The siren songs of science: Toward 
a taxonomy of scientific uncertainty for decisionmakers. Connecticut Law Review, 23, 567-627.

Westphal, S., Hendriks, F., \& Malik, M. (2015). Vertrauenswürdigkeit ohne Vertrauen? Wie die Kommunikation wissenschaftlicher Unsicherheiten die Bewertungen und Entscheidungen von Rezipienten beeinflusst [Trustworthiness but no trust? How communication of scientific uncertainty affects assessments and decisions of recipients]. In M. S. Schäfer, S. Kristiansen, \& H. Bonfadelli (Eds.), Wissenschaftskommunikation im Wandel [Science communication in a state of flux] (pp. 342-365). Cologne: Herbert von Halem.
Winter, S., \& Krämer, N. C. (2016). Who's right: The author or the audience? Effects of user comments and ratings on the perception of online science articles. Communications, 41(3), 339-360. https://doi.org/ 10.1515/commun-2016-0008

Wissenschaft im Dialog. (2018). Wissenschaftsbarometer 2018 [Science barometer 2018]. Berlin: Wissenschaft im Dialog.

Zehr, S. C. (2017). Scientific uncertainty in health and risk messaging. Oxford Research Encyclopedia of Communication, 1-27. https://doi.org/10.1093/ acrefore/9780190228613.013.215

\section{About the Authors}

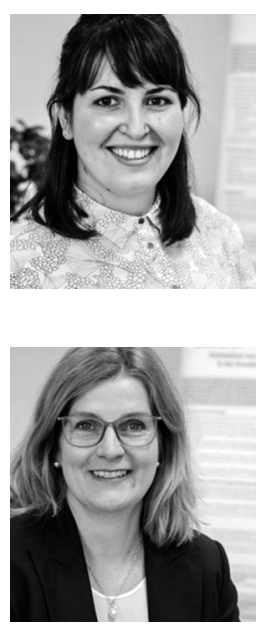

Friederike Hendriks is a Postdoctoral Researcher at the Institute of Psychology in Education and Instruction, University of Münster, Germany. Her research focuses on science communication, especially on people's trust in science and scientists, and researcher perspectives on their own communication of science.

Regina Jucks is a Professor of Psychology at the Institute of Psychology in Education and Instruction, at the University of Münster, Germany. She is also the Director of the Center for Teaching in Higher Education at the University of Münster, Germany. She received her PhD in Psychology from the University of Münster, Germany, in 2001, and completed her Habilitation (venia legendi in Psychology) in 2005. Her current research addresses communication and interaction in higher education mostly in digitized settings. 